\title{
Brief Introduction and Analysis of Hydropower Projects that Induced Resettlement in China
}

\author{
Yi Deng ${ }^{1, a}$,Sheng Yang ${ }^{1, b}$, Kui Wang ${ }^{1, c}$ \\ ${ }^{1}$ Chengdu Engineering Corporation Limited, Chengdu, Sichuan 610072, China \\ adengyi09752000@aliyun.com, b3535153@qq.com, wangkui1285@126.com,
}

\begin{abstract}
Keywords: Hydropower projects; policy; resettlement; inundation loses.
Abstract. For the rapid development of economy, China has seen more than 200 million kW capacity of hydropower plant installed and more than 55 billion $\mathrm{m} 3$ reservoir storage formed since 1950s. As a result, over 25 million resettlers have been wholly or partially affected. To displace and settle so many people is by no means a simple task. However, China has made great progress based on researches, studies, experiences and lessons drawn from the past over 60 years. To provide an overview of water resources and hydropower induced resettlement in China, this paper firstly introduces hydropower-induced resettlement briefly, and then examines the development of policies, laws and regulations. Afterwards, hydropower projects in Sichuan are taken as examples to show how inundation loses of hydropower projects develops. Moreover, some problems are posed and relevant suggestions are proposed in order to relocate those people more comfortably.
\end{abstract}

\section{Introduction}

In the past 64 years, China has seen more than 200 million $\mathrm{kW}$ capacity of hydropower plant installed and more than 55 billion $\mathrm{m} 3$ reservoir storage formed. As a result, over 25 million resettlers have been wholly or partially affected. To displace and settle so many people is by no means a simple task. After more than 60 years of research, study and summing up of experiences, hydropower projects induced resettlement in China have made extraordinary progress: policies and laws about hydropower projects induced resettlement have been made and gradually enriched; responsibilities for the ones who involve in the resettlement of people affected by hydropower projects have been defined more clearly; the compensation for those people have been more and more reasonable and for the benefit of local development, the number of people affected by a single project becomes less and less. Furthermore, numerous researchers and engineers are studying the dynamic compensation model for reservoir resettlement.

\section{Development and Reformation of Resettlement}

For more than 60s, the legal framework of hydropower projects induced resettlement is considerably perfect. And China is now paying great attention to legislation and reformation on the resettlement of people affected by hydropower projects. And we can divide the development of hydropower induced resettlement into three phases: before 1980s in planned economy era, 1980s to 1990s in transition period and after 2000s.

Before 1980s, China was in planned economy era, and people affected were displaced and resettled through administrative measures. Government took simple ways to relocate resources such as lands to displace affected people. The ideology of considering "projects are more important than resettlement" was responsible for the failures in hydropower projects induced resettlement. Planners ignored their legal interest and did not research deeply. This lead to many problems, including people displaced moved back and their life becoming worse and worse.

Since 1980s, China made a series of laws and polices on the basis of summing up experiences of resettlement. In 1984, an important design criterion was issued by the Ministry of Water Resources. After that, the State Council issued the first specialized polices: the Regulation on Compensation for Land Acquisition and Resettlement on Large and Medium-sized Water Conservancy and 
Hydroelectric Projects in 1991. In this document, the principle of compensating affected people firstly and then giving support to them was confirmed. The framework of polices on hydropower-induced resettlement was built after a design criterion about inundation of hydropower projects was released in 1996. Institutions and organizations serving to resettlement were eventually formed from that time.

After 2000s, China attached great importance to rural areas and put forward higher requirement in resettlement. In order to guarantee the legal right of resettlers, the Regulation on Compensation for Land Acquisition and Resettlement on Large and Medium-sized Water Conservancy and Hydroelectric Projects (1991) was updated in 2006. It expounds the compensation standards (especially land acquisition compensation), procedure and types of resettlement, resettlement management and monitoring. Afterwards, the National Development and Reform Commission issued "Specifications of resettlement planning and designing for hydroelectric project" and other 7 specifications on resettlement planning and designing, forming a relatively perfect system to guide planning and designing of hydropower-induced resettlement.

\section{Case Study: Resettlement in Sichuan Province, China}

Sichuan, which is located in west part of China, is abundant in hydropower resources. Its theoretical developable power capacity is about 143 million $\mathrm{kW}$, accounts for 21.1 percent of all Chinese theoretical power capacity. Technically developable power capacity is about 103 million $\mathrm{kW}$, accounts for 27.2 percent of that of China. And most of those hydropower resources are mainly distrusted in three rivers: Jinsha river, Yalong river and Dadu river. What's more, those rivers are three of the 13 large hydropower bases in China, which have been or are being built. Those three rivers, which respectively are the first, third and fifth largest hydropower bases of the 13, take over more than 63 percent of hydropower resources in Sichuan. All these rivers hydropower development will be exploited with a cascade development.

As a result of such plentiful hydropower resources, large amounts of hydropower projects have been and are being built, such as Xiluodu hydropower station and Xiangjiaba hydropower station in Jinsha river, Et hydropower station and Lhk hydropower station in Yalong river, Pbg hydropower station and Sjk hydropower station in Dadu river. And inevitably, those projects affect thousands of indigenous people, forcing them to be relocated in other places. Through many years of practicing and gathering experience, Sichuan has achieved great success in hydropower projects induced resettlement.

TABLE.1 BASIC INFORMATION ABOUT THESE HYDROPOWER STATIONS

\begin{tabular}{|c|c|c|c|c|c|c|c|c|c|}
\hline No & stations & $\begin{array}{c}\text { power capacity } \\
(\mathrm{MW})\end{array}$ & $\begin{array}{c}\text { current } \\
\text { situation }\end{array}$ & rivers & sections & $\begin{array}{c}\text { acquired } \\
\text { lands }\left(\mathrm{mu}^{\mathrm{b}}\right)\end{array}$ & $\begin{array}{c}\text { displaced } \\
\text { people }\end{array}$ & $\begin{array}{c}\text { Farmlands } \\
(\mathrm{mu})\end{array}$ & $\begin{array}{c}\text { wood lands } \\
(\mathrm{mu})\end{array}$ \\
\hline 1 & $\mathrm{Rd}$ & 400 & $\mathrm{PC}^{\mathrm{a}}$ & Yalong & upstream & 8942 & 619 & 1064 & 5345 \\
\hline 2 & Lhk & 3000 & $\mathrm{UC}$ & Yalong & middle & 181379.3 & 6287 & 5595.14 & 129979 \\
\hline 3 & $\mathrm{Et}$ & 3330 & $\mathrm{IO}$ & Yalong & downstream & 88054.6 & 31210 & 27424.7 & 37368.5 \\
\hline 4 & Sjk & 2000 & $\mathrm{UC}$ & Dadu & upstream & 76591.9 & 5940 & 11837.9 & 48007.1 \\
\hline 5 & $\mathrm{Ld}$ & 920 & $\mathrm{IO}$ & Dadu & middle & 3627 & 14840 & 4105.9 & 3818.5 \\
\hline 6 & $\mathrm{Pbg}$ & 3600 & $\mathrm{IO}$ & Dadu & downstream & 146518 & 107965 & 64446 & 9078 \\
\hline 7 & $\mathrm{Csj}$ & 390 & $\mathrm{PC}$ & $\mathrm{Csj}$ & - & 3388.7 & 137 & 263.3 & 2671.7 \\
\hline 8 & Zpp & 760 & $\mathrm{IO}$ & Min & - & 35073 & 35218 & 12427 & 7302 \\
\hline
\end{tabular}

${ }^{\mathrm{a}} \mathrm{PC}, \mathrm{UC}$ and $\mathrm{IO}$ is short for planned to be constructed, in operation and under constructed respectively ;

${ }^{\mathrm{b}} \mathrm{mu}$ is an area unit in Chinese, $15 \mathrm{mu}$ is equal to $10000 \mathrm{~m}^{2}$.

In order to study how hydropower inundation and construction area develops in different watershed and different period, a number of hydropower stations are researched here. Not only ones in the three river basins, but also ones in other watershed. To explore how inundation loses change in the same river, hydropower stations in upstream, middle and downstream are discussed. Table 1 shows some basic information about these hydropower stations.

Comparison in the Same River. To study the differences in the same river, we can examine hydropower stations in the same rivers but in different period and sections. According to the situation of hydropower stations, Stations can be divided into three phases. 
Take hydropower stations in Yalong and Dadu river as examples. The installed capacity of Rd, Lhk and Et hydropower stations are $400 \mathrm{MW}, 3000 \mathrm{MW}$ and $3300 \mathrm{MW}$ and that of $\mathrm{Sjk}$, Ld and Pbg are 2000MW, 920MW and 3600MW, their one capacity ( MW) caused lose are showed in table 2.

TABLE. 2 ONE CAPACITY ( MW) CAUSED LOSE OF THOSE HYDROPOWER STATIONS

\begin{tabular}{|c|c|c|c|c|c|}
\hline \multirow{2}{*}{ River } & $\begin{array}{c}\text { Hydropower } \\
\text { stations }\end{array}$ & $\begin{array}{c}\text { Land } \\
\text { (mu/MW) }\end{array}$ & $\begin{array}{c}\text { Farmland } \\
\text { (mu/MW) }\end{array}$ & $\begin{array}{c}\text { Wood land } \\
\text { (mu/MW) }\end{array}$ & $\begin{array}{c}\text { Person } \\
\text { ( person/MW) }\end{array}$ \\
\hline \multirow{3}{*}{ Yalong } & $\mathrm{Rd}$ & 22.36 & 2.66 & 13.36 & 1.55 \\
\cline { 2 - 6 } & $\mathrm{Lhk}$ & 60.46 & 1.87 & 43.33 & 2.10 \\
\cline { 2 - 6 } & $\mathrm{Et}$ & 26.44 & 8.24 & 11.22 & 9.37 \\
\hline \multirow{3}{*}{ Dadu } & $\mathrm{Sjk}$ & 38.30 & 5.92 & 24.00 & 2.97 \\
\cline { 2 - 7 } & $\mathrm{Ld}$ & 3.94 & 4.46 & 4.15 & 16.13 \\
\cline { 2 - 6 } & $\mathrm{Pbg}$ & 40.70 & 17.90 & 2.52 & 29.99 \\
\hline
\end{tabular}

According to data in table 2, we can clearly find out that land required by one MW in the same river from downstream to upstream decreases distinctly. This amount of land, farmland in Yalong river decreases from 26.44 and 8.24 to 22.36 and 2.66, in Dadu river decreases from 40.70 and 17.90 to 38.30 and 5.92. But wood land required by one MW increases from downstream to upstream extraordinarily, from 11.22 and 2.52 to 13.36 and 24.00 . This is the result of local area being rich in wood land but short of farmland and other resources.

What's more, the law that persons displaced by one MW drops off violently. In Yalong river, this data drops from 9.37 persons per MW in Et to 2.10 persons per MW in Lhk to 1.55 persons per MW in $\mathrm{Rd}$, this is 6 times downstream to upstream. Dadu river also follows this pattern, it drops from 29.99 persons per MW in Pbg to 16.13 persons per MW in Ld to 2.97 persons per MW in Sjk, 10 times downstream to upstream.

Comparison between Different Periods. According to the situation of hydropower stations, Stations can be divided into three phases. And every phase implies that the hydropower station is in relevant period. For example, IO is earlier than UC, and UC is earlier than PC. To research how hydropower projects inundation develops in different phases, inundation of hydropower stations in different period is examined. Table 3 shows their one capacity ( MW) caused lose.

TABLE.3 ONE CAPACITY ( MW) CAUSED LOSES

\begin{tabular}{|c|c|c|c|c|c|}
\hline Phase & $\begin{array}{c}\text { Hydropower } \\
\text { stations }\end{array}$ & $\begin{array}{c}\text { Land } \\
(\mathrm{mu} / \mathrm{MW})\end{array}$ & $\begin{array}{l}\text { Farmland } \\
(\mathrm{mu} / \mathrm{MW})\end{array}$ & $\begin{array}{c}\text { Wood land } \\
(\mathrm{mu} / \mathrm{MW})\end{array}$ & $\begin{array}{c}\text { Person } \\
\text { ( person/MW) }\end{array}$ \\
\hline \multirow{3}{*}{$\mathrm{PC}$} & $\mathrm{Rd}$ & 22.36 & 2.66 & 13.36 & 1.55 \\
\hline & $\mathrm{Csj}$ & 8.69 & 0.68 & 6.85 & 0.35 \\
\hline & summation & 15.61 & 1.68 & 10.15 & 0.96 \\
\hline \multirow{3}{*}{ UC } & Lhk & 60.46 & 1.87 & 43.33 & 2.10 \\
\hline & Sjk & 38.30 & 5.92 & 24.00 & 2.97 \\
\hline & summation & 51.59 & 3.49 & 35.60 & 2.45 \\
\hline \multirow{4}{*}{ IO } & Et & 26.44 & 8.24 & 11.22 & 9.37 \\
\hline & $\mathrm{Pbg}$ & 40.70 & 17.90 & 2.52 & 29.99 \\
\hline & $\mathrm{Zpp}$ & 46.15 & 16.35 & 9.61 & 46.34 \\
\hline & summation & 35.06 & 13.56 & 6.99 & 22.68 \\
\hline
\end{tabular}

From table 3, we can easily come to a conclusion that persons displaced by one MW reduces dramatically, from 22.68 persons per MW in IO phase to about 0.96 persons per MW in PC phase, 23.6 times IO to PC. And this is because most of the dam construction site and affected areas are in remote places where people are quite rare.

With respect to land, farmland and wood land required by one MW, the trend is a little comprehensive. Land required by one MW increases from IO to UC but decreases from UC to PC. Land required by one MW decreases from IO to UC to PC, that is from 13.56 to 3.49 to1.68, 8 times IO to PC. Wood land required by one MW of IO is less than UC and PC, but that in UC is the most.

\section{Experience and Suggestions}

Experience. According to the resettlement of hydropower induced resettlement in China and especially in Sichuan province, we can conclude that the success of hydropower induced resettlement is mainly from paying great attention to it, clear responsibility of every participant, powerful leadership and efficient management ability. Above all, comprehensive policies and legal systems can 
promote resettlement planning and social and economic research greatly so as to improve their income and the quality of life of displaced people.

In addition, the resettlement designing institutes are of great importance to resettlement planning and social and economic research. Their achievements play a crucial role in relocating people affected. The scheme and standard must be suitable to actual circumstances and solve real problems. This need engineers to be sophisticated and study further and discuss in depth.

\section{Suggestions.}

Resettlement without resource reallocation. Most of hydropower projects induced resettlers are farmers, and with hydropower stations construction site move to upstream of rivers, the vast majority of fertile and plain crop lands are inundated and leaves no more to those affected people. To maintain their life, new resettlement types without resources should be figured out and carried out. So far, a new resettlement type called "compensates displaced people year by year" has come into operation in some recently constructed hydropower stations. It compensates displaced people for the loss of farmlands and orchard lands by giving them money that amounts to the average annual output of farmlands and orchard lands year by year. But further studies are needed to confirm the compensation standard and years and other implementation.

Compensation standard to be unified. There are no polices or rules that give a uniform standard in compensating hydropower projects induced loss to indigenous people. At present, compensation standards in different provinces and counties are different. What is more incredible, compensation standards in one projects but different administrative districts are not the same. So, it is an urgent and pressing task for decision makers and planners to develop a more unprejudiced standard.

Public participation. Construction of hydropower projects will not only bring indigenous people benefits but also losses. Public have rights and duties to know and decide how to displace people affected. And it is unquestionable that displaced people are entitled to determine where to go and how to resettle within the law. Therefore, planners have to listen attentively to them and make plans comprehensively.

\section{References}

[1] Springer Berlin Heidelberg: Impacts of Large Dam: A Global Assessment Water Resources Development and Management, 2012.

[2] Shaoshan Zhang: Advances in Science and Technology of Water Resources,March-2006, pp. 1-6.( in Chinese )

[3] Yuefang Duan, Shawn Steil: Journal of Refugee Studies, vol.16(2003), pp. 422-443.

[4] Wanzhen Guo, Jiangping Zhang and Yi Deng: Journal of Hydroelectric Engineering, vol.31(2012), pp.1-4. ( in Chinese )

[5] Dan Li, Wanzhen Guo, Huanyong Liu, et. : Study on Reservoir Resettlement of Western China, 2010. ( in Chinese )

[6] Bryan Tilt, Yvonne Braun and Daming He:: Journal of Environmental Management, vol.90(2008), pp.249-257. 